\title{
Associative and repetition priming with the repeated masked prime technique: No priming found
}

\author{
S. E. Avons, Riccardo Russo, Caterina Cinel, Veronica Verolini, \\ Kevin Glynn, Rebecca McDonald, and Marie Cameron \\ University of Essex, Colchester, England
}

\begin{abstract}
Wentura and Frings (2005) reported evidence of subliminal categorical priming on a lexical decision task, using a new method of visual masking in which the prime string consisted of the prime word flanked by random consonants and random letter masks alternated with the prime string on successive refresh cycles. We investigated associative and repetition priming on lexical decision, using the same method of visual masking. Three experiments failed to show any evidence of associative priming, (1) when the prime string was fixed at 10 characters (three to six flanking letters) and (2) when the number of flanking letters were reduced or absent. In all cases, prime detection was at chance level. Strong associative priming was observed with visible unmasked primes, but the addition of flanking letters restricted priming even though prime detection was still high. With repetition priming, no priming effects were found with the repeated masked technique, and prime detection was poor but just above chance levels. We conclude that with repeated masked primes, there is effective visual masking but that associative priming and repetition priming do not occur with experiment-unique prime-target pairs. Explanations for this apparent discrepancy across priming paradigms are discussed. The priming stimuli and prime-target pairs used in this study may be downloaded as supplemental materials from mc.psychonomicjournals.org/content/supplemental.
\end{abstract}

Priming studies in which the lexical decision task has been used have repeatedly shown that presenting an associated prime word before a target word (e.g., bread-BUTTER) facilitates processing of the target, relative to conditions in which the target is preceded by an unrelated prime (e.g., Becker \& Killion, 1977; Davelaar \& Coltheart, 1975; de Groot, 1983; Meyer \& Schvaneveldt, 1971; for reviews, see McNamara, 2005; Neely, 1991). Priming has also been observed when the relationship between a prime and a target was purely semantic, such as category-exemplar priming (e.g., Fischler, 1977; Neely, 1977; Perea \& Rosa, 2002; Seidenberg, Waters, Sanders, \& Langer, 1984; for reviews, see Hutchison, 2003; Lucas, 2000). Associative priming can be observed when the stimulus onset asynchrony (SOA) varies from relatively long durations of $1 \mathrm{sec}$ or so down to very short values of $200 \mathrm{msec}$ (e.g., Henik, Friedrich, Tzelgov, \& Tramer, 1994; Smith, Bentin, $\&$ Spalek, 2001), suggesting that at least some contributing processes are extremely rapid, possibly automatic. However, associative priming can be modulated by varying task parameters such as the relatedness proportion, the proportion of word targets preceded by related primes. Increasing the relatedness proportion tends to increase priming only at longer SOAs (300 msec or greater), suggesting that strategic processes may be involved (e.g., de Groot, 1984; den Heyer, Briand, \& Dannenbring, 1983;
Henik et al., 1994; Hutchison, Neely, \& Johnson, 2001; Pecher, Zeelenberg, \& Raaijmakers, 2002; but see Bodner $\&$ Masson, 2003, for an exception).

Another technique used to limit strategic processing is masked priming, in which prime visibility - and, in the limit, participants' awareness of primes - is reduced by visual masking. Eliminating awareness of the prime also negates any contribution of episodic memory to priming. Typically, in masked priming studies, the prime is presented briefly $(50-60 \mathrm{msec})$, preceded by a visual mask consisting of repeated characters such as hash marks (\#\#\#\#) and followed immediately by the target, so that SOA corresponds to prime duration. Repetition priming is readily observed with this kind of presentation (Forster \& Davis, 1984; Forster, Mohan, \& Hector, 2003). Semantic or associative priming effects are less easy to detect with masked priming, and the strength of priming tends to increase with prime duration (de Groot, 1983; Perea \& Gotor, 1997; Perea \& Rosa, 2002; Rastle, Davis, MarslenWilson, \& Tyler, 2000). One possible explanation is that associative priming occurs only through awareness of the prime and that, as prime duration increases, so does the proportion of trials on which prime awareness occurs. Various methods have been used to address this problem, such as excluding participants who report prime awareness (de Groot, 1983), by discounting trials on which the prime 
and the target were identified (Pecher et al., 2002), or by showing that prime awareness was not positively related to priming (Bodner \& Masson, 2003). In all these cases, evidence of priming remained after attempts had been made to nullify the contribution of prime awareness.

The difficulty of demonstrating masked semantic priming in the strict absence of awareness became prominent as a result of controversial studies in the 1980s. These studies reported associative priming of word recognition from word primes that were so strongly masked that they were apparently undetectable (e.g., Carr, McCauley, Sperber, \& Parmelee, 1982; Dagenbach, Carr, \& Wilhelmsen, 1989; Fowler, Wolford, Slade, \& Tassinary, 1981; KempWheeler \& Hill, 1988; Marcel, 1983). However, there were a number of failures to replicate (e.g., Purcell, Stewart, \& Stanovich, 1983), and this prompted a methodological debate about determining threshold levels for the prime. Cheesman and Merikle (1984) distinguished between subjective awareness thresholds reported by participants and objective thresholds based on the ability to make forced choice decisions about masked items. In some circumstances, the objective threshold is lower than the subjective threshold, and priming may be observed below the higher subjective threshold, but not below the objective threshold. The measurement of objective thresholds requires allocating attention to the prime, rather than to the target, and may overestimate prime visibility during the priming task when participants respond only to the target. A further problem is that thresholds may vary throughout the duration of an experiment, so that apparent subliminal semantic priming may result from awareness of the primes on a proportion of trials (Holender, 1986; Purcell et al., 1983). An additional consideration is that studies in which CRT technology is used permit a minimal display increment of $10-20 \mathrm{msec}$, limited by the refresh cycle of the display hardware. With this coarse quantization of display parameters, it may be difficult to locate critical thresholds precisely. For all these reasons, it is difficult to establish that truly subliminal semantic or associative priming occurs.

Robust priming in the absence of awareness would provide a useful experimental tool for manipulating semantic processes in ways that leave no explicit memory record. This would be useful for studying word processing, and also as a technique for manipulating memory without creating an episodic record. However, despite extensive efforts, studies in which an attempt has been made to demonstrate associative priming while rigorously eliminating the contribution of awareness have not been successful (see McNamara, 2005, for a comprehensive review). Some recent studies of masked categorical priming do seem to meet this criterion but have used binary classification judgments where the prime and the target were congruent or incongruent with respect to the response (e.g., Draine \& Greenwald, 1998; Greenwald, Klinger, \& Shuh, 1995; see also Naccache \& Dehaene, 2001, for related findings in numerical cognition). Thus, response congruence, rather than semantic activation of the prime, may be the source of priming (Klinger, Burton, \& Pitts, 2000).

A new masking paradigm showing categorical priming effects with primes presented at or near threshold was recently described by Wentura and Frings (2005). In this method, primes were presented repeatedly but were effectively masked by alternating the prime with a masking string on successive refresh cycles. Two eight-letter masking strings (mask1, mask2) were used on each trial, both consisting of random consonants. To avoid edge effects, the prime word (five to six letters) was extended to a string of eight letters by the addition of consonants to the beginning and end of the word. The first presentation of the prime was preceded by mask1, and thereafter the prime and the mask 2 were alternated on successive frames, for a total of 10 prime-mask 2 cycles. Wentura and Frings applied this masking paradigm to a categorical priming task, in which the masked primes were one of four category names, followed by a lexical decision task in which word targets were category members and nonword targets were misspelled category members. Prime detection was measured using the same display of the prime, followed by a two-alternative forced choice test of category names. A row of question marks appeared in place of the target following the last mask 2 display. For observers for whom prime detection was low, Wentura and Frings (2005, Experiments 1 and 2) reported substantial negative priming for low-dominance exemplars. Response times (RTs) were about $30 \mathrm{msec}$ longer following the related category prime. Negative priming of low-dominance exemplars was also found when response accuracy was measured using a response window procedure requiring speeded responses within 400-550 msec (Experiment 3), and when naming latencies were measured (Experiment 4). Highdominance exemplars showed no priming with lexical decision RTs (Experiments 1-3) but positive priming with naming latency (Experiment 4).

No significant priming effects were found in a more conventional masked priming condition in which the prime was presented for two cycles $(28 \mathrm{msec})$, followed by a mask (Experiment 2), although priming in this condition did not differ significantly from that obtained using repeated prime-mask cycles. When the category prime was made visible at the same SOA, positive categorical priming was observed for low-dominance exemplars, but not for high-dominance exemplars (Experiment 1).

Several features of this masking paradigm are of interest. First, prime detection performance was impressively low in the majority of participants, but the priming effects were large and detectable in small samples. Second, the technique was devised for standard CRT displays with a fixed refresh rate. The technique does not require timeconsuming threshold-setting procedures, and the appropriate display conditions require only standard display technologies and software. If robust, this masking technique can be adapted for use in a wide variety of experimental settings. Third, Wentura and Frings (2005) hinted that the effectiveness of the repeated prime accumulates through repeated presentations, although they did not test this directly. They concluded that their technique "allows for an increase in the length of prime exposure to a level comparable with that in a standard supraliminal priming experiment while simultaneously preventing awareness of the prime for the majority of participants" (Wentura \& 
Frings, 2005, p. 116). If this is true, increasing the number of prime-mask cycles should increase the extent of priming, without necessarily increasing awareness.

In the present study, we investigated the effectiveness of the repeated masked priming technique, using the familiar paradigm in which associative primes precede targets in a lexical decision task. This method differs in two main ways from the categorical priming studied by Wentura and Frings (2005). First, the linguistic relationship between the prime and the target differs. Associative primes are selected by the frequency with which the prime as a cue elicits the target, and there is no consistent semantic relationship between them, as there is in categorical priming. Second, there is an important methodological difference in the recurrence of primes during the experiment. In most associative priming studies, each prime-target combination is unique and usually is presented once, whereas in categorical priming studies a small number of primes and targets are repeatedly presented. In Wentura and Frings's study, only four primes and 24 word targets were used. For these reasons, we might not expect to find comparable results in associative and categorical priming paradigms. Our aim here was to examine the application of the repeated masked prime technique to associative priming (Experiments 1, 2, 3, and 5) and repetition priming (Experiment 6). Our experiments had three aims: (1) to determine whether associative priming or repetition priming with experimentunique prime-target pairs can be reliably obtained using repeated masked primes, (2) to determine the effectiveness of visual masking with alternating masks and primes, and (3) to determine whether the amount of priming increases with the number of prime-mask cycles.

\section{GENERAL METHOD}

\section{Participants}

All the participants were undergraduate and postgraduate students at the University of Essex, recruited from panels maintained by the Psychology Department. All the participants were native English speakers or otherwise fluent English speakers who had been educated in English.

\begin{abstract}
Apparatus
In all the experiments reported here, the participants were run individually in one of two small experimental booths measuring $135 \times$ $220 \mathrm{~cm}$. Each booth was lit by an overhead fluorescent light providing illuminance of 135 lux measured on a standard reflectance in the vertical plane at the location of the display screen. The stimuli were displayed using two Mitsubishi Diamond Plus 19-in. color monitors, each driven by a Macintosh G3 computer at a refresh rate of $70 \mathrm{~Hz}$. Unless otherwise specified, stimuli were displayed in black on a white background with a luminance of 30 or $39 \mathrm{~cd} / \mathrm{m}^{2}$, depending on which monitor was used. Viewing distance was approximately $60 \mathrm{~cm}$. Software was written in C, incorporating the VideoToolbox subroutines (Pelli, 1997). In all the experiments, timing routines were used to check the display durations, and trials were discarded if the display durations indicated that additional frames had been displayed. Masking stimuli, primes, and targets were displayed in 24-point Courier font, so that uppercase letters were approximately $5 \mathrm{~mm}$ high and $5 \mathrm{~mm}$ apart.
\end{abstract}

\section{Materials}

Priming task. The stimulus set used in the associative priming experiments consisted of 180 semantic associates and 180 pairs with nonword targets. Associate pairs were chosen from two databases: the University of South Florida norms (Nelson, McEvoy, \& Schreiber, 2004) and the Birkbeck word association norms (Moss \& Older, 1996). Pairs were chosen with a minimum forward strength of 0.4 , and where possible, associates were chosen so that the word targets would be singular concrete nouns. The primes (cue words) were unrestricted in terms of grammatical category. Items were selected and sometimes modified to be familiar to British speakers (e.g., SHINGLE-roof changed to TILE-roof), and items were presented with British spelling. Cue and target words were between four and seven letters in length. The mean forward association strength of the 180 related pairs was $0.58(S D=0.15)$. Kučera-Francis frequency was available for 175 targets, with a mean value of 76 per million $(S D=$ 112). Unrelated word pairs were formed by randomly recombining the prime-target pairs. This recombination was carried out across blocks of stimuli, so that each target was preceded by a dedicated related or unrelated prime, and the prime was not repeated in conjunction with any other target. Where repetition priming was investigated (Experiment 6), the prime words were the same as the targets, and related/unrelated trials were constructed in the same way.

The remaining 180 items with nonword targets consisted of 90 word-nonword pairs and 90 nonword-nonword pairs. These items were based on words selected from the Nelson et al. (2004) database that were not included in the word target set. Prime and target nonwords were made by changing one or two letters in corresponding words. The words from which prime and target nonwords were derived were unrelated. Items with nonword targets were included purely as foils in the lexical decision task. The complete list of word targets with related and unrelated primes and the nonword target stimuli are provided in Appendix A.

On each trial, flanking consonant letters were selected randomly online and were placed at the beginning and end of the prime word. In Experiments 1-3, the flanking letters made the prime string up to 10 characters long, and in other experiments, the number of flanking letters was variable. Two masking stimuli were generated online. Mask 1 and Mask 2 were consonant strings made by selecting consonants at random without replacement from the set of 20 consonants in the English alphabet (excluding Y). On any trial, the prime string and the masks were always the same length (for Experiments 1-3 this was always 10 letters). The prime and mask strings were displayed in uppercase text, the target in lowercase.

Prime detection task. Another set of 80 primes and target words were used in the prime detection task. These included 40 word-word associate pairs that were selected from published norms but had association strengths below 0.4 (e.g., SUEDE-leather). In the remaining 40 items, a nonword taken from the appendices of Borowsky and Besner (1993) replaced the cue word and was presented as the prime (e.g., DONAMY-castle). Items were displayed in the same font and case as for the priming task. The items used for the prime detection task are listed in Appendix B.

\section{Procedure}

Priming task. There were 360 trials, 180 with word targets and 180 with nonword targets, presented in a random order. Of the 180 trials with word targets, 120 used related primes and 60 used unrelated primes, giving a relatedness proportion of .67. Each trial began with the display of a fixation point ("+") for $500 \mathrm{msec}$, followed by a 200-msec blank screen. Mask 1 was then displayed for one frame, followed by a number of cycles of the prime followed by Mask 2, each displayed for one frame (we will refer to these as prime-mask2 cycles). Thus, in a presentation with 2 prime-mask 2 cycles, the sequence of events would be mask1-prime-mask2-prime-mask 2 . In our experiments, we used displays with 10 and 20 prime-mask 2 cycles. Since each refresh cycle lasted $14.3 \mathrm{msec}$, the time interval from the first display of the prime to the onset of the target was 286 and $572 \mathrm{msec}$ for 10- and 20-cycle displays, respectively. Immediately afterward, the target string was displayed and remained visible until the participant responded. The participants responded to word and nonword targets by pressing the "/" or " $z$ " key, respec- 
tively, on the computer keyboard, which were appropriately marked. They were instructed to rest their forefingers on the keys so that they could respond rapidly. Following the procedure described by Bodner and Masson (2003), feedback was provided after each response. The word "correct" or "wrong" was displayed in the center of the screen in 12-point font. A tone sounded if a response was incorrect or if the response time (RT) was longer than $1,500 \mathrm{msec}$.

Before the priming task, there was a short practice of 40 trials, with 10 related prime-target word pairs, 10 unrelated prime-target pairs, and 20 nonword-nonword pairs.

Prime detection task. With the exception of Experiment 4, in which the prime strings were not alternated with consonant masks, the priming task was followed by a prime detection task. Here, the display was identical to that in the priming task, but the task was to classify the prime as a word or a nonword. The target was always a word. Eighty trials were given, including 40 word and 40 nonword primes, with 20 word and nonword primes in each half. The responses from all 80 prime detection trials were analyzed; similar results were obtained when only the last 40 trials were included in the analysis.

\section{Treatment of Data}

Priming task. Trials were excluded if there were anomalies in the timing of displays, so that the prime or mask was displayed for additional frames. Irregularities in display timing occurred on $0.9 \%$ of the trials in Experiment 1 and 1.3\% of the trials in Experiment 2 and were eliminated entirely by modifying the software in later experiments. Trials were also excluded if the RT was invalid, indicating either an anticipation (RT $<300 \mathrm{msec}$ ) or a delayed response (RT $>$ $1,500 \mathrm{msec}$ ). Exclusion on the basis of RTs followed the procedure of Bodner and Masson (2003) and was consistent with the feedback tone. Error rates were computed across all trials with correct display timing, where RTs were valid. Mean RTs were based on correct valid trials.

Prime detection task. No response deadline was set in the prime detection task, and error rates were measured across all trials on which the display timing was correct.

\section{EXPERIMENT 1}

In the masked condition, each prime string (prime plus flanking consonants) was presented for 10 cycles, alternating with the second consonant mask. These presentation conditions are comparable to those in Wentura and Frings (2005, Experiment 1), which showed clear categorical priming.

\section{Method}

Participants. Twenty-four participants ( 16 of them female) were used, with a mean age of 21.5 years $(S D=4.06)$.

Design. Prime type (related or unrelated prime) was manipulated within subjects. The primes appearing with each word target were counterbalanced across participants, so that, across the whole experiment, each target was displayed with its corresponding related prime on two thirds of the occasions (i.e., for 16 participants) and with its unrelated prime on one third of the occasions.
Procedure. The participants first completed the practice of 40 trials. This was followed by the associative priming procedure in which the prime was displayed using 10 prime-mask 2 cycles. Finally, the participants completed the prime detection procedure, using the same repeated mask display. All other details were as described above.

\section{Results and Discussion}

Associative priming task. The mean accuracy and mean RTs for word and nonword targets under masked prime and visible prime conditions are provided in Table 1. For the masked condition, the mean RTs showed a minimal advantage for related primes, but the difference was not significant by a related samples $t$ test, for either RT $[t(23)<$ $1.0]$ or the accuracy measure $[t(23)=1.11, p>.05]$.

Prime detection task. Performance at lexical decision on the primes was also very low, as is shown in Table 1. Mean percent correct accuracy over the last 40 trials was compared against the chance value of $50 \%$, using a onesample $t$ test. The result was not significant $[t(23)<1]$.

This experiment failed to show associative priming when the prime was repeatedly displayed for 10 primemask2 cycles, although Wentura and Frings (2005) reported evidence of categorical priming with similar displays. Their account of repeated masked priming suggests that the degree of priming should increase with the number of prime-mask cycles, since, in their view, the effectiveness of priming depends on the total display time of the prime string. Therefore, in Experiment 2, we varied the number of repetitions of the prime, so that on half the trials the prime was displayed for 10 cycles and on the other half for 20 cycles.

\section{EXPERIMENT 2}

\section{Method}

Participants. Thirty participants ( 21 of them female) were recruited from the undergraduate and postgraduate populations at the University of Essex. The mean age was 19.8 years $(S D=2.6)$.

Design. The two independent variables, prime type (related or unrelated) and prime display time (10 prime-mask 2 cycles or 20 prime-mask2 cycles) were manipulated within subjects. Thus, there were 60 related and 30 unrelated trials at each display time. The items allocated to each condition were counterbalanced across participants. The four conditions formed by crossing prime type and display time were presented in a randomized order.

Procedure. In this and all the subsequent experiments, for both priming and prime detection tasks, the target was shown in lowercase letters, with ampersands added to the beginning and end of the string to make the total length 10 characters. Presenting the target in this form has been shown to increase sensitivity to priming by slowing target responses (Bodner \& Masson, 2003). The participants

Table 1

Performance on the Associative Priming and Prime Detection Tasks for Experiments 1-3

\begin{tabular}{|c|c|c|c|c|c|c|c|c|c|c|c|c|c|c|c|}
\hline & \multirow{3}{*}{$\begin{array}{l}\text { Display } \\
\text { Cycles }\end{array}$} & \multicolumn{6}{|c|}{ Response Times (msec) } & \multicolumn{6}{|c|}{ Accuracy ( $\%$ Correct) } & \multirow{2}{*}{\multicolumn{2}{|c|}{$\begin{array}{c}\text { Prime Detection } \\
\text { (\% Correct) }\end{array}$}} \\
\hline & & \multicolumn{2}{|c|}{ Unrelated } & \multicolumn{2}{|c|}{ Related } & \multicolumn{2}{|c|}{ Priming } & \multicolumn{2}{|c|}{ Unrelated } & \multicolumn{2}{|c|}{ Related } & \multicolumn{2}{|c|}{ Priming } & & \\
\hline & & $M$ & $S E$ & $M$ & $S E$ & $M$ & $S E$ & $M$ & $S E$ & $M$ & $S E$ & $M$ & $S E$ & $M$ & $S E$ \\
\hline Experiment 1 & 10 & 577 & 13 & 576 & 11 & 2 & 4 & 98.2 & 0.4 & 97.9 & 0.3 & -0.3 & 0.3 & 51.5 & 1.1 \\
\hline Experiment 2 & 10 & 653 & 11 & 658 & 12 & -6 & 7 & 96.5 & 0.6 & 96.3 & 0.4 & -0.2 & 0.6 & 49.2 & 1.9 \\
\hline Experiment 2 & 20 & 652 & 12 & 640 & 12 & 12 & 7 & 97.7 & 0.6 & 95.9 & 0.7 & $-1.8^{* *}$ & 0.6 & 49.0 & 1.3 \\
\hline Experiment 3 & 20 & 661 & 10 & 658 & 10 & 3 & 3 & 96.5 & 0.4 & 96.2 & 0.4 & -0.3 & 0.3 & 50.0 & 0.5 \\
\hline
\end{tabular}

Note-In all conditions, the prime string was 10 characters long. ${ }^{* *} p<.01$. 
first completed the practice of 40 trials. This was followed by the associative priming task. Finally, the participants completed the prime detection procedure. All other details were as described above.

\section{Results and Discussion}

Associative priming task. The mean correct RTs to word targets were analyzed with a $2 \times 2$ (prime type $\times$ number of prime-mask cycles) ANOVA. The results showed no effect of prime type $\left[F(1,29)=0.37, M S_{\mathrm{e}}=\right.$ 703.6, $p>.05]$ and no effect of the number of display cycles $\left[F(1,29)=2.65, M S_{\mathrm{e}}=915.2, p>.05\right]$. The interaction between these variables was in the expected direction, showing apparently increased priming with an increased number of prime-mask cycles, which approached significance $\left[F(1,29)=3.40, M S_{\mathrm{e}}=651.6, p=.076\right]$. Within both the 10- and 20-cycle conditions, individual $t$ tests were used to examine the effects of priming but failed to reach significance for 10 display cycles $[t(29)<1.0]$ or for 20 display cycles $[t(29)=1.76, p=.089]$.

The accuracy of responses on valid trials in which responses occurred within the response deadlines was also examined. A $2 \times 2$ (display time $\times$ prime relatedness) within-subjects ANOVA showed that there was no effect of display time on accuracy $[F(1,29)<1]$ but there was a marginal effect of prime relatedness $[F(1,29)=$ $\left.4.16, M S_{\mathrm{e}}=7.36, p=.051\right]$ and a significant interaction $\left[F(1,29)=4.96, M S_{\mathrm{e}}=3.62, p<.05\right]$. Response accuracy in the 10-cycle condition did not differ between unrelated and related primes, as was shown by a $t$ test $[t(29)<1]$. However, for the 20-cycle displays, response accuracy was higher on trials with unrelated primes than on those with related primes $[t(29)=2.99, p<.01]$. Thus, in the 20 cycle condition, responses to word targets were faster but less accurate when they were preceded by related primes, suggesting a speed-accuracy trade-off, rather than an influence of the prime.

Prime detection task. Prime detection accuracy for each display time condition is provided in Table 1. Data were collected from the last 40 trials, half of which were presented with 10 cycles of priming and half with $20 \mathrm{cy}$ cles. The data for each condition were compared against the expected mean of $50 \%$, using a one-sample $t$ test, and in both cases the result was nonsignificant $[t(29)<1]$.

Like Experiment 1, this experiment failed to show evidence of associative priming using the repeated masked prime technique. An assumption of Wentura and Frings (2005) was that repeated masked priming increases with the number of prime-mask 2 cycles, so here we varied the number of cycles, hoping to find stronger priming effects with an increase in the number of cycles. For the RT data, priming was apparently increased when primes were displayed for an increased number of cycles, although the priming effect itself did not reach significance. More critically, the error rates were inconsistent in showing increased errors to related targets. Thus, there is doubt that even a weak priming effect was observed here.

In Experiment 3, we again attempted to find evidence of priming, this time using only the 20 -cycle display condition. We greatly increased power by increasing the number of participants. In addition, we screened participants by a second, associative priming task, using visible primes. This procedure was based on Dagenbach et al.'s (1989) study of masked semantic priming. They observed that not everyone shows semantic priming even under ideal conditions and argued that it was futile to look for evidence of weak masked priming effects in participants who did not demonstrate the potentially much stronger effects of unmasked priming.

\section{EXPERIMENT 3}

\section{Method}

Participants. One hundred three participants were run through the experiment. Of these, 22 failed to show priming with visible primes, leaving 81 participants ( 47 of them female), with a mean age of 25.8 years $(S D=8.2)$. Care was taken that the allocation of items to conditions was fully counterbalanced across the 81 participants who remained in the experiment.

Procedure. The experimental session began with an associative priming task with visible primes. The participants then completed a short practice of 40 trials, followed by the associative priming task (360 trials), both using repeated masked primes with 20 primemask 2 cycles. Finally, the prime detection task was completed.

\section{Results and Discussion}

Associative priming task. The priming effect for RTs was minimal and failed to reach significance $[t(80)<1]$. Likewise, there was no difference in accuracy for targets preceded by related and unrelated primes $[t(80)<1]$.

Prime detection task. Lexical decision for the masked word in the prime detection task was at chance levels and did not differ from the expected value of $50 \%$ $[t(80)<1]$.

These results, like those of Experiments 1 and 2, provide no evidence of associative priming with repeated masked primes. Our failure to detect priming suggests that our repeated masking effectively obscured the prime word and prevented the extraction of visual information about the prime. Given the repeated failure to find priming, it is necessary to show that we could detect associative priming if the primes were made visible. Therefore, in Experiment 4 , the prime was presented in a more conventional way, by displaying it without preceding or following masks, but using the same total display time as in the masked conditions (see Wentura \& Frings, 2005, Experiment 1).

\section{EXPERIMENT 4}

In Experiments 1-3, repeated masked primes were displayed for 10 or 20 prime-mask 2 cycles. In Experiment 4, the prime was presented either for $143 \mathrm{msec}$ (10 screen refreshes) followed by a 143-msec delay, giving an SOA of $286 \mathrm{msec}$, or for $286 \mathrm{msec}$ ( 20 screen refreshes), followed by a $286-\mathrm{msec}$ delay before the target, giving an SOA of $572 \mathrm{msec}$.

Another concern of this experiment was the role of the flanking letters that surrounded the prime. When presenting repeated masked primes, Wentura and Frings (2005) added one or two random consonants at the beginning and end of the prime word, to make all the prime strings 8 letters in length. This was essential in their experiment in order to 
conceal the length of the four primes, as well as to minimize edge effects in masking. Following the same rationale, in Experiments 1-3 we added consonants to make prime strings 10 letters long. In the case of short, 4-letter primes (.27 of the total), this amounted to adding three random consonants to the beginning and end of the prime. It is probable that flanking letters reduce the effectiveness of the prime. In Experiment 4, we explored the effect of flanking letters on visible primes, using three flanking letter conditions. In the no-flanker condition, primes were presented without any flanking letters. In the two-flanker condition, one random consonant was placed at each end of the prime. In the third condition, flanking letters were added to make the prime string 10 letters in length, as in the previous experiments. It should be noted that Wentura and Frings always used flanking letters with repeated masked primes but apparently used primes without flanking letters in their visible control condition (Wentura \& Frings, 2005, Experiment 1).

\section{Method}

Participants. Thirty-six adult native English speakers (20 of them female) were recruited from students and staff at the University of Essex. Each participant was allocated to one of the three flanking conditions. The mean age of the participants was 23.9 years $(S D=$ 9.2). Two participants were replaced because the proportion of invalid trials on word lexical decisions exceeded $10 \%$.

Design. The experiment used a mixed design. The number of letters flanking the prime $(0,2$, or $>2)$ was varied between subjects. The independent variables of prime-target SOA (286 or $572 \mathrm{msec}$ ) and prime-target relation (associated or unrelated) were varied within subjects. Care was taken so that for all three groups of participants, every target contributed to the related and unrelated prime conditions and appeared in the two SOA conditions.

Procedure. The associative priming task was administered as in Experiment 3, with the following modification. Each prime string was displayed continuously for 10 or 20 refresh cycles and without a premask or a postmask. After the prime string, the screen was blank for the same duration that the prime string had been displayed. The lowercase target was flanked by ampersands, as in Experiments 2-3.

\section{Results and Discussion}

The data were filtered by excluding all errors and RTs less than $300 \mathrm{msec}$ or greater than $1,500 \mathrm{msec}$. The mean RTs for each word and nonword condition are given in Table 2.

RTs were analyzed with a $3 \times 2 \times 2$ mixed ANOVA with number of flanking letters $(0,2$, or $>2)$ as the betweensubjects factor and prime type (related/unrelated) and prime-target SOA as the two within-subjects factors. This showed significant main effects of prime type $[F(1,33)=$ 25.49, $\left.M S_{\mathrm{e}}=614.4, p<.001\right]$ and of prime-target SOA $\left[F(1,33)=4.49, M S_{\mathrm{e}}=757.2, p<.05\right]$. There was a significant interaction between prime type and number of flanking letters $[F(1,33)=9.20, p=.001]$, indicating that the extent of priming varied between the three flanking conditions. No other main effects or interactions were found.

The results were further analyzed by calculating the priming effect (unrelated RT - related RT) for each participant in each of the SOA conditions and testing whether this was significantly different from zero, using a onesample $t$ test. Priming effects were found in the no-flanker condition with 10 prime-mask 2 cycles $[t(11)=4.16, p<$ $.005]$ and also for 20 cycles $[t(11)=4.78, p<.005]$. There was also a priming effect with two flanking letters, but only at the longer SOA $[t(11)=2.77, p<.05]$. No other priming effects were found.

The accuracy data were consistent with the RT data. Again, responses to words were analyzed by a $3 \times 2 \times$ 2 mixed ANOVA with number of flanking letters $(0,2$, or $>2$ ) as the between-subjects factor and prime type (related/unrelated) and prime-target SOA as the two within-subjects factors. This showed a significant priming effect $\left[F(1,33)=20.1, M S_{\mathrm{e}}=5.58, p<.001\right]$ and a significant interaction between flanking condition and prime type $[F(1,33)=4.51, p<.05]$, where the accuracy advantage for related targets was largest for the condition with no flanking letters. Considering pairwise comparisons of accuracy scores across related and unrelated primes, only the 10-cycle, no-flanker condition showed a significant difference $[t(11)=4.90, p<.001]$.

These results show clearly that associative priming effects occurred with our stimuli, when primes were presented without forward and backward masking. However, associative priming was reduced by embedding the prime in flanking letters. With no flanking letters, we found robust priming at both prime durations. As was mentioned above, Wentura and Frings (2005) used primes without flanking letters to observe the effect of priming with conventional visible primes. Under these conditions, we readily found evidence of priming. However, with just two flanking letters and a prime duration of 10 cycles, we found no priming, although weak priming was found with 20 cycles. Priming was weak or absent when more than two flanking letters were used.

The results confirm that under clear viewing conditions, with no flanking letters and no masking, our stimuli gen-

Table 2

Experiment 4: Associative Priming With Flanking Letters but Without Repeated Masks

\begin{tabular}{|c|c|c|c|c|c|c|c|c|c|c|c|c|c|}
\hline \multirow{3}{*}{$\begin{array}{c}\text { No. Flanking } \\
\text { Letters }\end{array}$} & \multirow{3}{*}{$\begin{array}{c}\mathrm{SOA} \\
(\mathrm{msec})\end{array}$} & \multicolumn{6}{|c|}{ Response Times (msec) } & \multicolumn{6}{|c|}{ Accuracy ( $\%$ Correct) } \\
\hline & & \multicolumn{2}{|c|}{ Unrelated } & \multicolumn{2}{|c|}{ Related } & \multicolumn{2}{|c|}{ Priming } & \multicolumn{2}{|c|}{ Unrelated } & \multicolumn{2}{|c|}{ Related } & \multicolumn{2}{|c|}{ Priming } \\
\hline & & $M$ & $S E$ & $M$ & $S E$ & $M$ & $S E$ & $M$ & $S E$ & $M$ & $S E$ & $M$ & $S E$ \\
\hline \multirow[t]{2}{*}{0} & 286 & 569 & 17 & 529 & 15 & $41^{* *}$ & 10 & 92.7 & 1.3 & 97.3 & 0.7 & $4.5^{* * *}$ & 0.9 \\
\hline & 572 & 560 & 9 & 509 & 10 & $50^{* *}$ & 11 & 95.0 & 1.0 & 97.2 & 1.1 & 2.2 & 1.3 \\
\hline \multirow[t]{2}{*}{2} & 286 & 571 & 16 & 574 & 24 & -3 & 11 & 96.1 & 1.4 & 97.2 & 1.0 & 1.1 & 1.8 \\
\hline & 572 & 578 & 20 & 561 & 22 & $17^{*}$ & 6 & 96.4 & 1.3 & 97.8 & 0.6 & 1.4 & 1.1 \\
\hline \multirow[t]{2}{*}{$>2$} & 286 & 592 & 15 & 581 & 12 & 11 & 7 & 94.7 & 2.0 & 96.9 & 0.5 & 2.3 & 1.7 \\
\hline & 572 & 579 & 13 & 570 & 12 & 9 & 10 & 97.5 & 0.9 & 96.5 & 1.0 & -0.9 & 1.3 \\
\hline
\end{tabular}

$$
{ }^{*} p<.05 . \quad{ }^{* *} p<.01 . \quad{ }^{* * *} p<.001 .
$$


erated substantial associative priming with brief presentations and short SOAs. However, adding flanking letters to the prime, even to the minimal extent of adding one consonant at the beginning and end of the prime, reduced the extent of priming. Indeed, we failed to detect priming with an SOA of $286 \mathrm{msec}$ and just two flanking letters. The number of flanking letters here was less than that in Wentura and Frings's (2005) repeated masked prime conditions. It is not clear, therefore, that they would have found priming effects if they had used unmasked primes with flanking letters.

The implications for repeated masked priming are unclear. One argument would be that if no priming is found with brief presentations without repeated masks, there is little point in looking for priming when there is additional masking from repeated primes. However, this may be too strong a claim. Under unmasked conditions in which the prime is visible, the flanking letters are also clearly visible, whereas with repeated masked priming, the flanking letters added to the prime are themselves masked (by Mask 1 and the repeated Mask 2) and are perceived as a temporal blur. Nevertheless, there is clearly a case for evaluating repeated masked priming with reduced numbers of flanking letters, as will be described in Experiment 5 below.

The presence of visible flanking letters may reduce priming by delaying semantic activation arising from the prime, so that it arrives too late to facilitate target identification, especially at short SOAs. Alternatively, adding flanking letters to a briefly presented prime could obscure the prime and prevent identification altogether. To test the latter, we asked 10 participants to read the primes embedded in 10-letter strings and presented under the conditions of Experiment 4. The results showed that mean performance was $76 \%$ correct identification in the most difficult condition ( $\mathrm{SOA}=286 \mathrm{msec}$, unrelated targets), rising to $90 \%$ in the easiest condition ( $\mathrm{SOA}=286 \mathrm{msec}$, related targets). Thus, flanking letters do not necessarily prevent prime identification. The interpretation we prefer is that the visible flanking letters in Experiment 4 delay identification of the prime, because an additional process is required to parse the flanking letters before the prime can be processed. Thus, information from the prime arrives too late to facilitate the following lexical decision.

\section{EXPERIMENT 5}

One possible reason for our failure to detect associative priming with repeated masked primes (Experiments 1-3) is that prime effectiveness was reduced by the flanking consonants added to the prime string. In Experiment 4, we showed that this was indeed the case for associative primes that were presented briefly without pre- or postmasks. Thus, associative priming might be observed with repeated masked primes if the number of flanking letters was reduced. We examined this possibility by using prime strings that had no flanking letters (Experiment 5A) or that had one flanking letter at the beginning and end of each prime (Experiment 5B). As in Experiment 2, we looked for evidence of associative priming, using the repeated masked prime method in which the prime was presented for 10 and 20 prime-mask 2 cycles.

\section{Method}

Participants. Twenty-four participants (14 of them female) contributed to Experiment 5A. Their mean age was 22.3 years $(S D=$ 7.3). Thirty participants (19 of them male) took part in Experiment $5 \mathrm{~B}$, with a mean age of 21.5 years $(S D=3.2)$. Both sets of participants were drawn from students at he University of Essex. One participant in Experiment 5A and 3 in Experiment 5B were replaced because their error rates exceeded $10 \%$.

Design. In each experiment, there were two within-subjects independent variables: the type of prime (related or unrelated) and the number of prime-mask 2 cycles ( 10 or 20 ).

Materials. The pairs of prime-target items were the same as those used in Experiments 1-3. In the flanking condition (Experiment 5B), one randomly chosen consonant was appended to the beginning and end of the prime, with the constraints that (1) the letter S never followed the prime and (2) the flanking letters did not match the corresponding letters in the masks.

Procedure. The procedure followed closely that in Experiment 2. The participants first completed a short practice of 40 trials, using the same procedure and flanking condition as those in the main experiment. This was followed by the associative priming task (360 trials), in which the participants made lexical decisions to the target, and then by a prime detection procedure ( 80 trials), in which the participants made lexical decisions to the prime.

\section{Results and Discussion}

Associative priming task. Trials were eliminated if the RT was less than $300 \mathrm{msec}$ or greater than $1,500 \mathrm{msec}$. These trials accounted for $1.2 \%$ of the total for Experiment $5 \mathrm{~A}$ and $1.4 \%$ for Experiment $5 \mathrm{~B}$. The mean accuracy of the valid trials and the mean RTs on correct valid trials are shown in Table 3.

With respect to the latency data, a $2 \times 2$ repeated measures ANOVA was run with priming (related or unrelated) and number of prime mask cycles as the factors. For Experiment $5 \mathrm{~A}$, there was no effect of prime duration $[F(1,23)=$ $\left.3.41, M S_{\mathrm{e}}=466.5, p>.05\right]$ or of priming $[F(1,23)<1]$, and the interaction also failed to reach significance $[F(1,23)=$ 1.05]. In Experiment 5B, the effect of priming again failed to reach significance $\left[F(1,29)=2.23, M S_{\mathrm{e}}=660.1, p>\right.$ $.05]$, and there was no effect of prime duration $[F(1,29)<$ $1]$ and again no interaction $[F(1,29)<1]$. A paired samples $t$ test was run comparing the mean RTs to targets preceded by unrelated and related primes in the 20-cycle condition of Experiment 5B. The result of this test also failed to reach significance $[t(29)=1.52, p=.122]$.

A 2 (prime type: related or unrelated) $\times 2$ (prime duration: 10 or 20 prime-mask 2 cycles) repeated measures ANOVA was run on the accuracy data from Experiments 5A and 5B separately. There were no significant main effects or interactions in Experiment 5A (all $F$ ratios $<1$ ). In Experiment 5B, the effect of prime duration failed to reach significance $\left[F(1,29)=1.44, M S_{\mathrm{e}}=6.12\right.$, $p<.05$ ], as did the effects of priming and the interaction (in both cases, $F<1$ ). Therefore, under these conditions, there was no effect of a repeated masked prime on the accuracy of a following lexical decision task.

Once again, in this experiment, we failed to find clear evidence of associative priming (1) in Experiment 5A with no flanking letters or (2) in Experiment 5B with one flanking letter at the beginning and end of each prime letter string, with prime display conditions similar to those used by Wentura and Frings (2005). 
Table 3

Performance on Priming and Prime Detection Tasks for Experiments 5 (Associative Priming) and 6 (Repetition Priming)

\begin{tabular}{|c|c|c|c|c|c|c|c|c|c|c|c|c|c|c|c|c|}
\hline & \multirow{3}{*}{$\begin{array}{l}\text { Display } \\
\text { Cycles }\end{array}$} & \multirow{3}{*}{$\begin{array}{c}\text { No. } \\
\text { Flankers }\end{array}$} & \multicolumn{6}{|c|}{ Response Times (msec) } & \multicolumn{6}{|c|}{ Accuracy (\% Correct) } & \multirow{2}{*}{\multicolumn{2}{|c|}{$\begin{array}{c}\text { Prime Detection } \\
\text { (\% Correct) }\end{array}$}} \\
\hline & & & \multicolumn{2}{|c|}{ Unrelated } & \multicolumn{2}{|c|}{ Related } & \multicolumn{2}{|c|}{ Priming } & \multicolumn{2}{|c|}{ Unrelated } & \multicolumn{2}{|c|}{ Related } & \multicolumn{2}{|c|}{ Priming } & & \\
\hline & & & $M$ & $S E$ & $M$ & $S E$ & $M$ & $S E$ & $M$ & $S E$ & $M$ & $S E$ & $M$ & $S E$ & $M$ & $S E$ \\
\hline \multirow[t]{2}{*}{ Experiment 5A } & 10 & 0 & 615 & 19 & 619 & 20 & -4 & 6 & 96.8 & 0.7 & 96.6 & 0.4 & -0.2 & 0.7 & 52.2 & 1.7 \\
\hline & 20 & 0 & 612 & 20 & 606 & 20 & 6 & 8 & 96.8 & 0.9 & 97.5 & 0.5 & 0.7 & 1.0 & 52.7 & 1.5 \\
\hline \multirow[t]{2}{*}{ Experiment 5B } & 10 & 2 & 654 & 21 & 651 & 20 & 3 & 6 & 95.8 & 0.9 & 95.9 & 0.7 & 0.1 & 1.1 & 51.5 & 1.4 \\
\hline & 20 & 2 & 658 & 22 & 647 & 21 & 11 & 7 & 96.5 & 0.7 & 96.3 & 0.5 & -0.2 & 0.8 & 51.2 & 1.3 \\
\hline \multirow[t]{2}{*}{ Experiment 6} & 20 & 0 & 645 & 11 & 639 & 12 & 6 & 5 & 97.4 & 0.6 & 96.9 & 0.5 & -0.5 & 0.6 & $55.1^{* *}$ & 1.5 \\
\hline & 20 & 2 & 651 & 12 & 655 & 12 & -4 & 6 & 96.3 & 0.7 & 96.2 & 0.6 & -0.1 & 0.6 & 53.1 & 1.6 \\
\hline
\end{tabular}

${ }^{* *} p<.01$,

Prime detection task. Mean accuracy for each flanking condition and number of repeated prime-mask cycles is shown in Table 3. Prime detection was very low, even in Experiment 5A, in which there were no flanking letters. A one-sample $t$ test was used to compare mean accuracy against the expected chance level of .5. In Experiment 5A, with no flanking letters, detection approached significance with the 20 -cycle display $[t(23)=1.78, p=.088]$, but not with a 10 -cycle display $[t(23)=1.30, p=.21]$. In Experiment 5B with just two flanking letters, prime detection was not significantly above chance with either 10 or 20 cycles $[t(29)=1.08$ and $t(29)=0.90$, respectively]. There was no effect of the number of prime-mask cycles on prime detection in Experiment $5 \mathrm{~A}[t(23)<1.0]$, or in Experiment $5 \mathrm{~B}[t(29)<1]$. This shows that even with no flanking letters or just two flanking letters, a prime word is effectively masked by alternating displays of the prime and a mask of random consonants.

\section{EXPERIMENT 6}

In Experiment 6, we looked for evidence of repetition priming with repeated masked primes. In repetition priming, all the information in the prime is available in the target, so that priming can potentially occur at the orthographic, morphemic lexical, or semantic level. Evidence of priming would, therefore, not indicate the locus of the effect. However, failure to find any evidence of priming with repetition priming would suggest that none of these sources of information was available and that processing of the prime was severely restricted with repeated masked presentations.

\section{Method}

Participants. Thirty-six participants (28 of them female) with a mean age of 21.4 years $(S D=3.61)$ took part in this experiment. All the participants were native English speakers or otherwise fluent English speakers who had been educated in English.

Design. A two-factor repeated measures design was used, in which the factors were the number of flanking letters ( 0 or 2$)$ and the relationship between the prime and the target. On two thirds of the word trials, the prime and the target were the same; on one third of the trials, they were different.

Materials. In this experiment, the target words were also used as primes. In the related condition, the prime and the target were the same word. In the unrelated condition, the primes and target items were recombined, with the constraint that the recombined primes and targets were always the same length. The words that were presented in related and unrelated pairs were rotated across participants. Half of the primes were presented without flanking letters, and the other half were preceded and followed by a single flanking letter, as in Experiment 5. The items that were presented with and without flanking letters were counterbalanced across participants. Nonword targets and their primes were re-paired so that each prime and target was the same length, and, if necessary, a nonword was altered to facilitate this. Nonword targets were always preceded by a prime that was different.

In the prime detection task, word primes were the same as the following target. Half the primes were presented without flanking letters; half were presented with one flanking letter at each end. The word targets appearing in each flanking condition and each priming condition were counterbalanced across participants.

Procedure. The experimental session began with a short practice of 40 trials, in which, for half the word targets, the prime was the same word. The main experiment consisted of 360 trials, in which, on each trial, a repeated masked prime was shown for 20 cycles, followed by a target that required a lexical decision response. After this, the participants completed the prime detection task of 80 trials.

\section{Results and Discussion}

Repetition priming task. Trials on which RTs were $<300 \mathrm{msec}$ or longer than $1,500 \mathrm{msec}$ were discarded ( $0.68 \%$ of the total). For the remaining trials, mean accuracy was computed for each condition, as is reported in Table 3.

The RTs to word targets were analyzed with a repeated measures 2 (flanker condition) $\times 2$ (priming condition) ANOVA. This showed a significant effect of flanker type, with shorter RTs in the no-flanker condition $[F(1,35)=$ $\left.8.12, M S_{\mathrm{e}}=512.1, p<.01\right]$. However, there was no effect of priming condition $[F(1,35)<1]$ and no interaction between prime type and flanker condition $[F(1,35)=1.58$, $\left.M S_{\mathrm{e}}=580.5, p>.05\right]$. Lexical decisions to the target appeared to be more difficult when the prime had flanking letters, here showing increased latency. It is possible that this arose because unflanked primes provided a better cue to the location and length of the target word that was embedded in the string of ampersands. However, there was no indication of any priming effect.

Accuracy, which was high in all the conditions, was analyzed with a repeated measures 2 (flanker condition) $\times$ 2 (priming condition) ANOVA. This showed that responses were marginally more accurate in the no-flanker condition $\left[F(1,35)=3.96, M S_{\mathrm{e}}=8.13, p=.054\right]$. However, there was no indication of any priming effect and no interaction between the number of flanking letters and priming condition [in both cases, $F(1,35)<1]$.

Prime detection task. In the no-flanking condition, the mean accuracy was $.55(S E=.015)$, which was significantly above chance by a one-sample $t$ test $[t(35)=3.49, p<.01]$. In the flanking condition, mean performance was .53 ( $S E=$ 
$.016)$, which fell just short of significance $[t(35)=1.97$, $p=.057]$. In this prime detection task, word primes were always identical to their targets; nonword primes were not. So any visual similarity between the prime and the target could be used to support prime detection. Above-chance performance does not indicate that word primes were identified or accessed lexically or semantically.

Priming as a function of detection. In Wentura and Frings (2005), negative priming of atypical category members used as targets was found only among participants who performed at chance levels on prime detection. We adopted the same procedure, dividing the participants into two groups according to their scores on prime detection in each flanking condition. For the no-flanking condition, the participants were divided into two groups: a lowdetection group $(n=22)$ with a mean $d^{\prime}=-0.018$ and a mean accuracy $=.497(S E=.01)$, and a high-accuracy group $(n=14)$ with a mean $d^{\prime}=0.772$ and a mean accuracy $=.637(S E=.018)$. Similarly, in the condition with two flanking letters, the low-detection group $(n=25)$ had a mean $d^{\prime}=-0.11$ and a mean accuracy $=.48(S E=$ $.011)$, and the high-accuracy group $(n=11)$ had a mean $d^{\prime}=0.877$ and a mean accuracy $=.648(S E=.016)$. We then considered priming for each flanking condition, conditional on prime detection performance. The mean RTs and extent of priming are provided in Table 4.

No significant priming was found for either flanking condition when the participants who scored high or low in prime detection were considered. However, there was a suggestion of a weak positive priming effect among low- $d^{\prime}$ participants in the no-flanking condition, although this did not reach significance. This might be expected if there were subliminal repetition priming using the repeated masked priming technique. However, some caution is required here, since restricting the analysis to a subset of participants violated the counterbalancing of stimuli across conditions in our design, although this is less of a problem for Wentura and Frings's study (2005), in which all the participants were tested on all the prime-target combinations.

\section{GENERAL DISCUSSION}

In this series of experiments, we have searched for evidence of associative priming on lexical decision, where each prime was presented by alternating it with a random consonant mask on successive frames, a masking method first described by Wentura and Frings (2005). Despite extensive efforts, we have failed to demonstrate associative priming using this repeated masked prime technique. A marginally significant RT advantage for related primes was observed with 20 prime-mask cycles in Experiment 2 (where the error data are inconsistent with a priming account), but this failed to replicate in Experiment 3. In Experiment 4, we found that in a conventional priming paradigm, in which unmasked primes were presented for the same total duration and prime-mask SOA, priming was impaired by the addition of flanking letters to the prime. Thus, the failure to find priming in Experiments 1-3 could be due to the presence of a number of flanking letters obscuring a masked prime, rather than being an effect of repeated masked priming. However, in Experiment 5, we again failed to detect priming when repeated masked primes were presented without flanking letters or with just two flanking letters. In all these experiments with repeated masked primes, prime detection was low and was not significantly different from chance. Thus, the repeated masked prime method certainly produces effective masking but does not produce priming effects that are strong enough to be reliably detected using associative priming. Finally, in one last attempt to find evidence of any kind of priming with repeated masked primes, we could detect no significant repetition priming when primes and targets were the same word, using primes with no flanking letters or with two flanking letters. There was a tendency toward weak positive priming with no flanking letters if high- $d$ ' participants were excluded, but across this subset of participants, the presentation conditions were unbalanced across target stimuli. Our conclusion is that in a conventional priming paradigm in which there are many primes and targets that are presented just once, associative or semantic repeated masked priming either does not occur or is very weak.

Of course, the failure to find priming effects may be due to a lack of power in the experimental designs. To test this, we calculated the power to detect a modest 20 -msec priming effect, using the standard deviations of the difference scores (unrelated RT - related RT) for each condition of each experiment. The standard deviations varied between the $17.8 \mathrm{msec}$ observed in Experiment 1 and $37.8 \mathrm{msec}$ for the 10-cycle condition in Experiment 2. In all the conditions, the power to detect a $20-\mathrm{msec}$ priming effect was high: For the 20-cycle condition in Experiment 5A, the calculated power was .74 , but it was above .8 for all the other conditions and above 9 for Experiments 1, 3, and 6 and for the 10-cycle conditions in Experiments 5A and 5B.

Table 4

Repetition Priming for Participants With High and Low Performance at Prime Detection

\begin{tabular}{|c|c|c|c|c|c|c|c|c|c|c|c|}
\hline & \multirow[b]{3}{*}{$n$} & & & \multicolumn{6}{|c|}{ Response Times (msec) } & \multirow[b]{3}{*}{$t$} & \multirow[b]{3}{*}{$p$} \\
\hline & & \multicolumn{2}{|c|}{$d^{\prime}$} & \multicolumn{2}{|c|}{ Unrelated } & \multicolumn{2}{|c|}{ Related } & \multicolumn{2}{|c|}{ Priming } & & \\
\hline & & $M$ & $S E$ & $M$ & $\overline{S E}$ & $M$ & $\overline{S E}$ & $M$ & $\overline{S E}$ & & \\
\hline \multicolumn{12}{|c|}{ Zero flankers } \\
\hline Low $d^{\prime}$ & 22 & -0.018 & 0.053 & 651 & 15 & 638 & 15 & 13 & 7 & 1.90 & .072 \\
\hline High $d^{\prime}$ & 14 & 0.772 & 0.110 & 637 & 16 & 641 & 21 & -4 & 8 & -0.47 & .645 \\
\hline \multicolumn{12}{|c|}{ Two flankers } \\
\hline Low $d^{\prime}$ & 25 & -0.110 & 0.058 & 656 & 14 & 658 & 14 & -2 & 7 & -0.23 & .819 \\
\hline High $d^{\prime}$ & 11 & 0.877 & 0.105 & 639 & 27 & 647 & 25 & -8 & 8 & -0.96 & .362 \\
\hline
\end{tabular}


Wentura and Frings (2005) reported negative priming effects of about $30 \mathrm{msec}$, and any effect of comparable magnitude would certainly have been detected.

To encourage associative priming effects, we used a lexical decision task with a relatively high relatedness proportion (.67), following the claim by Bodner and Masson $(2001,2003)$ that relatedness proportion affects even masked priming. Related prime-target pairs were selected from two established sets of norms with high association values of 0.4 or greater. When primes were made visible by presenting them without masks for the same duration and SOA (Experiment 4), strong priming effects were seen. Thus, strong associative priming can be obtained with our materials and procedures at short SOAs. But the presence of flanking letters around the prime reduced or eliminated priming from visible primes. Indeed, in the condition with just two flanking letters (roughly equivalent to the manipulation used for repeated masked primes in Wentura \& Frings, 2005) and a 286-msec SOA (equivalent to their 10 prime-mask 2 cycle displays), we failed to find priming. Wentura and Frings (2005, Experiments 1 and 2) used primes without flanking letters in their visible prime control condition and, apparently, also in their standard masked condition, so we do not know what the contribution of flanking letters would have been in these cases. It is possible that flanking letters around the prime would have less effect in their task, since primes were of roughly equal length and all were known in advance. The main concern for our study was the possibility that excessive use of flanking letters in Experiments 1-3 precluded repeated masked priming. Experiment 5 showed that without flanking letters, priming could not be detected.

In the prime detection task, in which participants made a lexical decision task on the primes, we found no evidence that associative repeated masked primes were detectable. In contrast, Wentura and Frings (2005) reported that about one third of their participants were able to identify the primes in a forced choice identification task. Priming was found after these participants were excluded, providing evidence for an influence of undetectable primes. The differences between the priming effects observed in our experiments, in which reliable priming was not found, and those reported by Wentura and Frings may be due to small differences in presentation conditions across the two studies or to the marked procedural differences between categorical priming, using repeated presentations of a small set of primes, and associative or repetition priming using a large number of unique prime-target pairs.

First, with respect to the visual-masking technique, we adhered closely to the method outlined by Wentura and Frings (2005). Prime and mask strings were alternated at the same refresh rate. All the prime and mask strings were displayed in uppercase letters and were 10 letters in length in the present study. Wentura and Frings used shorter masks and prime strings of 8 letters, which was possible because their longest primes had only six characters, whereas ours varied between four and seven characters. The two masks were composed of random consonants, and the prime string was made from the prime, positioned centrally, with random consonants added at each end. Moreover, the masks were generated independently on each trial, so that perceptual learning of the masking stimuli was not possible. From their article, it is not clear whether Wentura and Frings used different masks and/or different flanking letters on the many trials on which the same prime was displayed. If not, it may have been easier for participants to learn to discriminate the masked prime strings. In our experiments, we used the fixed-width Courier font so that the letters of the masks and prime strings would superimpose. The MS-DOS text font used by Wentura and Frings has similar properties. Thus, an attempt was made to get the masking conditions as close as possible to those of Wentura and Frings, but it is possible that some feature of our displays may have increased visual masking and, thereby, eliminated semantic or associative priming. One appealing property of the repeated masked technique is that it seems easy to reproduce. However, visual parameters determining the temporal integration of the masking and prime strings are likely to play a part, and these may require more precise specification.

Second, Wentura and Frings (2005) looked for evidence of subliminal priming in a paradigm in which the target word was preceded by a category name, rather than by an associate. The type of priming alone may account for the differences between our results: Repeated masked primes may allow category priming, but not associative priming. To us, this seems unlikely, because (1) the masking technique restricts early visual processing of words, in ways that we expect to be common to all lexical decision priming tasks, and (2) we know that associative priming occurs when strategies are restricted - for example, with short SOAs. In addition, it is unlikely that semantic effects are observed when associative priming is absent because, in studies in which these two forms of priming have been compared, associative priming appears to have been at least as strong as pure semantic priming (Hutchison, 2003; Lucas, 2000). Nevertheless, it is conceivable that priming by semantic overlap of features could occur when associative priming is absent. Some accounts (e.g., Joordens \& Becker, 1997) have proposed that semantic and associative priming use different mechanisms and that these priming effects occur at the semantic level or at the lexical level. To test this, we investigated repeated masked repetition priming (Experiment 6) when there was complete overlap of prime and target semantic features. No clear evidence of repetition priming was found, at least not when lexical decision was used as the task, although Wentura and Frings reported clear category-exemplar priming effects in three experiments using lexical decision.

Another consideration is that Wentura and Frings's (2005) study used only four prime tokens and each prime was repeatedly presented throughout the experiment. In contrast, in our experiments, primes and targets were experiment unique and unpredictable. One possible explanation is that partial priming, based on the identification of individual letters, was sufficient to influence target lexical decision in Wentura and Frings's study. Using a Stroop priming paradigm, Kouider and Dupoux (2004) demonstrated that presenting masked color names gave rise to congruency effects when colors were classified with 
a manual response. Several features of their experiment were common to those in Wentura and Frings's study: (1) There was a small set of prime words, (2) participants were informed about the nature of the primes, and (3) the SOA was comparably short (287 or $301 \mathrm{msec}$ ). Kouider and Dupoux showed that in the appropriate priming conditions, Stroop interference was the same for true color words (ROUGE) and orthographically similar nonwords (RUGOE). They proposed that this was because participants identified a subset of letters from the prime and used these to construct the primes. Moreover, they reported masking levels at which lexical decision was poor but letter identification was well above chance. According to their partial awareness hypothesis, "participants rely on their expectations and the partial information available regarding the identity of the primes" (Kouider \& Dupoux, 2004, p. 78). In our view, the restricted set of primes and targets in the Wentura and Frings study make priming from partial information a possibility, but this would be most unlikely in a conventional associative priming study with unique presentations of many prime-target pairs.

As far as we are aware, the present article reports the first attempt to demonstrate associative priming using the repeated masked prime technique introduced by Wentura and Frings (2005). Our results, the product of extensive investigations, show no consistent priming and no evidence that increasing the total prime duration increases priming. As with all studies of priming close to threshold, it is possible that small differences in prime presentation, masking, or display parameters may account for the differences across studies. Further work is needed to determine whether this is the case. However in our opinion, it is most likely that in their studies of repeated masked priming, Wentura and Frings established conditions in which partial information of a prime drawn from a very restricted set could influence target processing and that these conditions are not found in more conventional priming paradigms.

\section{AUTHOR NOTE}

The authors gratefully acknowledge financial support for this work from the Economic and Social Research Council of the United Kingdom (Research Grant RES-000-22-1404).We are grateful to Sally Andrews, Steve Joordens, Ken Forster, and one anonymous reviewer for helpful comments on a previous version of the manuscript. Correspondence concerning this article should be addressed to S. E. Avons, Department of Psychology, University of Essex, Wivenhoe Park, Colchester, Essex CO4 3SQ, England (e-mail: savons@essex.ac.uk).

\section{REFERENCES}

Becker, C. A., \& Killion, T. H. (1977). Interaction of visual and cognitive effects in word recognition. Journal of Experimental Psychology: Human Perception \& Performance, 3, 389-401.

Bodner, G. E., \& Masson, M. E. J. (2001). Prime validity affects masked repetition priming: Evidence for an episodic resource account of priming. Journal of Memory \& Language, 45, 616-647.

Bodner, G. E., \& Masson, M. E. J. (2003). Beyond spreading activation: An influence of relatedness proportion on masked semantic priming. Psychonomic Bulletin \& Review, 10, 645-652.

BorowsKy, R., \& BESNER, D. (1993). Visual word recognition: A multistage activation model. Journal of Experimental Psychology: Learning, Memory, \& Cognition, 19, 813-840.

Carr, T. H., McCauley, C., Sperber, R. D., \& Parmelee, C. M.
(1982). Words, pictures and priming: On semantic activation, conscious identification, and the automaticity of information processing. Journal of Experimental Psychology: Human Perception \& Performance, 8, 757-777.

Cheesman, J., \& Merikle, P. M. (1984). Priming with and without awareness. Perception \& Psychophysics, 36, 387-395.

Dagenbach, D., Carr, T. H., \& Wilhelmsen, A. (1989). Task-induced strategies and near-threshold priming: Conscious influences on unconscious perception. Journal of Memory \& Language, 28, 412-443.

Davelaar, E., \& Coltheart, M. (1975). Effects of interpolated items on the association effect in lexical decision tasks. Bulletin of the Psychonomic Society, 6, 269-272.

DE Groot, A. M. B. (1983). The range of automatic spreading activation in word priming. Journal of Verbal Learning \& Verbal Behavior, 22, 417-436.

DE Groot, A. M. B. (1984). Primed lexical decision: Combined effects of the proportion of related prime-target pairs and the stimulus-onset asynchrony of prime and target. Quarterly Journal of Experimental Psychology, 36A, 253-280.

den Heyer, K., Briand, K., \& Dannenbring, G. L. (1983). Strategic factors in a lexical-decision task: Evidence for automatic and attention-driven processes. Memory \& Cognition, 11, 374-381.

Draine, S., \& Greenwald, A. G. (1998). Replicable unconscious semantic priming. Journal of Experimental Psychology: General, 127, 286-303.

FISCHLER, I. (1977). Associative facilitation without expectancy in a lexical decision task. Journal of Experimental Psychology: Human Perception \& Performance, 3, 18-26.

Forster, K. I., \& DAVIS, C. (1984). Repetition priming and frequency attenuation in lexical access. Journal of Experimental Psychology: Learning, Memory, \& Cognition, 10, 680-698.

Forster, K. I., Mohan, K., \& Hector, J. (2003). The mechanics of masked priming. In S. Kinoshita \& S. J. Lupker (Eds.), Masked priming: The state of the art (pp. 3-37). New York: Psychology Press.

Fowler, C. A., Wolford, G., Slade, R., \& Tassinary, L. (1981). Lexical access with and without awareness. Journal of Experimental Psychology: General, 110, 341-362.

Greenwald, A. G., Klinger, M. R., \& Shuh, E. S. (1995). Activation by marginally perceptible ("subliminal") stimuli: Dissociation of unconscious from conscious cognition. Journal of Experimental Psychology: General, 124, 22-42.

Henik, A., Friedrich, F. J., Tzelgov, J., \& Tramer, S. (1994). Capacity demands of automatic processes in semantic priming. Memory \& Cognition, 22, 157-168.

HolENDER, D. (1986). Semantic activation without conscious identification in dichotic listening, parafoveal vision and visual masking: A survey and appraisal. Behavioral \& Brain Sciences, 9, 1-66.

Hutchison, K. A. (2003). Is semantic priming due to associative strength or feature overlap? A microanalytic review. Psychonomic Bulletin \& Review, 10, 785-813.

Hutchison, K. A., Neely, J. H., \& Johnson, J. D. (2001). With great expectations: Can two wrongs prime a right? Journal of Experimental Psychology: Learning, Memory, \& Cognition, 27, 1451-1463.

Joordens, S., \& BECKER, S. (1997). The long and short of semantic priming effects in lexical decision. Journal of Experimental Psychology: Learning, Memory, \& Cognition, 23, 1083-1105.

Kemp-Wheeler, S. M., \& Hill, A. B. (1988). Semantic priming without awareness: Some methodological considerations and replications. Quarterly Journal of Experimental Psychology, 40A, 671-693.

Klinger, M. R., Burton, P. C., \& Pitts, G. S. (2000). Mechanisms of unconscious priming: I. Response competition, not spreading activation. Journal of Experimental Psychology: Learning, Memory, \& Cognition, 26, 441-455.

Kouider, S., \& Dupoux, E. (2004). Partial awareness creates the "illusion" of subliminal semantic priming. Psychological Science, 15, 75-81.

LuCAs, M. (2000). Semantic priming without association: A metaanalytic review. Psychonomic Bulletin \& Review, 7, 618-630.

MArCEL, A. J. (1983). Conscious and unconscious perception: Experiments on visual masking and word recognition. Cognitive Psychology, 15, 197-237.

McNamara, T. P. (2005). Semantic priming: Perspectives from memory and word recognition. New York: Psychology Press. 
Meyer, D. E., \& SchVAneveldt, R. W. (1971). Facilitation in recognizing pairs of words: Evidence of a dependence between retrieval operations. Journal of Experimental Psychology, 90, 227-234.

Moss, H. E., \& OldER, L. (1996). Birkbeck word association norms. Hove, U.K.: Psychology Press.

Naccache, L., \& Dehaene, S. (2001). Unconscious semantic priming extends to novel unseen stimuli. Cognition, 80, 223-237.

Neely, J. H. (1977). Semantic priming and retrieval from lexical memory: Roles of inhibitionless spreading activation and limitedcapacity attention. Journal of Experimental Psychology: General, 106, 226-254

NeELY, J. H. (1991). Semantic priming effects in visual word recognition: A selective review of current findings and theories. In D. Besner \& G. W. Humphreys (Eds.), Basic processes in reading: Visual word recognition (pp. 264-336). Hillsdale, NJ: Erlbaum.

Nelson, D. L., McEvoy, C. L., \& Schreiber, T. A. (2004). The University of South Florida free association, rhyme, and word fragment norms. Behavior Research Methods, Instruments, \& Computers, 36, 402-407.

Pecher, D., Zeelenberg, R., \& RaAijmakers, J. G. W. (2002). Associative priming in a masked perceptual identification task: Evidence for automatic processes. Quarterly Journal of Experimental Psychology, 55A, 1157-1173.

Pelli, D. G. (1997). The VideoToolbox software for visual psychophysics: Transforming numbers into movies. Spatial Vision, 10, 437-442.

Perea, M., \& Gotor, A. (1997). Associative and semantic priming effects occur at very short stimulus-onset asynchronies in lexical decision and naming. Cognition, 62, 223-240.
Perea, M., \& Rosa, E. (2002). The effects of associative and semantic priming in the lexical decision task. Psychological Research, 66, 180-194.

Purcell, D. G., Stewart, A. L., \& Stanovich, K. E. (1983). Another look at semantic priming without awareness. Perception \& Psychophysics, 34, 65-71.

Rastle, K., Davis, M. H., Marslen-Wilson, W. D., \& Tyler, L. K. (2000). Morphological and semantic effects in visual word recognition: A time course study. Language \& Cognitive Processes, 15, 507-537.

Seidenberg, M. S., Waters, G., Sanders, M., \& Langer, P. (1984). Pre- and post-lexical loci of contextual effects on word recognition. Memory \& Cognition, 12, 315-328.

Smith, M. C., Bentin, S., \& Spalek, T. M. (2001). Attention constraints of semantic activation during visual word recognition. Journal of Experimental Psychology: Learning, Memory, \& Cognition, 27, 1289-1298.

Wentura, D., \& Frings, C. (2005). Repeated masked category primes interfere with related exemplars: New evidence for negative semantic priming. Journal of Experimental Psychology: Learning, Memory, \& Cognition, 31, 108-120.

\section{SUPPLEMENTAL MATERIALS}

The priming stimulli and prime-target pairs from this article may be downloaded as supplemental materials from mc.psychonomic-journals .org/content/supplemental.

APPENDIX A

Items Used in the Semantic Priming Task

\begin{tabular}{|c|c|c|c|c|c|}
\hline \multicolumn{6}{|c|}{ (A1) Unrelated and Related Primes for Each Word Target } \\
\hline Unrelated & Related & Target & Unrelated & Related & Target \\
\hline CHEF & WAVES & ocean & ROAST & SHRUB & bush \\
\hline TWIG & TOES & foot & HAMMER & SLEDGE & snow \\
\hline SIRLOIN & STOPPER & plug & HANDBAG & CROOK & thief \\
\hline STEP & FUNERAL & death & ROMAN & DIAMOND & ring \\
\hline REFLECT & ELASTIC & band & NURSE & DEMON & devil \\
\hline QUID & DUNE & sand & DEMON & HUSBAND & wife \\
\hline FANTASY & CHEDDAR & cheese & HUSBAND & MARSH & swamp \\
\hline ATOMIC & SENTRY & guard & SHRUB & DAGGER & knife \\
\hline SPOON & ATOMIC & bomb & FARM & TORSO & body \\
\hline KNOB & ANTLERS & deer & GLOBE & BLAZE & fire \\
\hline STOPPER & CAVITY & tooth & BOULDER & THORN & rose \\
\hline CANDID & SALT & pepper & CRUST & TALON & claw \\
\hline KIWI & PANE & window & SILVER & CRUST & bread \\
\hline PAIL & SIRLOIN & steak & CROOK & CAPTAIN & ship \\
\hline BLOSSOM & TILE & roof & PRISON & GLOBE & world \\
\hline CORE & SPOON & fork & MARROW & TRASH & garbage \\
\hline TOES & REEF & coral & PARSON & PRISON & jail \\
\hline TILE & BOUNCE & ball & BUCKLE & DUSK & dawn \\
\hline PHANTOM & FOREST & tree & LINK & FLOOD & water \\
\hline SOCK & JOURNEY & trip & CUTLASS & HANDBAG & purse \\
\hline CHEDDAR & CANDID & camera & ESTUARY & FARM & animal \\
\hline HOUSE & TWIG & branch & BUTCHER & COOKIE & biscuit \\
\hline SALT & AVENUE & street & $\mathrm{CASH}$ & ROAST & beef \\
\hline LAMP & STEEPLE & church & TRASH & WASHER & dryer \\
\hline AVENUE & BALLAD & song & PLASMA & $\mathrm{CASH}$ & money \\
\hline ELASTIC & BANQUET & feast & SKULL & CRATER & moon \\
\hline ZEBRA & TOASTER & oven & BANNER & PARSON & vicar \\
\hline CAVITY & TOAD & frog & CRATER & ALCOHOL & drink \\
\hline PLANET & KNOB & door & VAGRANT & CLAP & hands \\
\hline TRUCK & PAIL & bucket & TIMBER & BUTCHER & meat \\
\hline RECORD & STEP & stair & CARTON & FILM & movie \\
\hline HARE & MOWER & lawn & FLEX & MONSOON & rain \\
\hline BROTHER & LAMP & light & POLAR & SOFA & couch \\
\hline
\end{tabular}


APPENDIXA (Continued)

\begin{tabular}{|c|c|c|c|c|c|}
\hline Unrelated & Related & Target & Unrelated & Related & Target \\
\hline BLOUSE & QUID & pound & BROTH & POLAR & bear \\
\hline PEDAL & BLOUSE & shirt & HOCKEY & SHEET & paper \\
\hline CIRCLE & HARE & rabbit & ROAR & ARTERY & vein \\
\hline JOURNEY & PHANTOM & opera & ALARM & TABLE & chair \\
\hline FOREST & LOFT & attic & DRAM & ICING & cake \\
\hline ANTLERS & ZEBRA & stripe & FILM & JIGSAW & puzzle \\
\hline MOWER & LIBRARY & book & MINER & CARTON & milk \\
\hline LIBRARY & WICK & candle & QUIVER & MULE & donkey \\
\hline PANE & TRUCK & lorry & COMB & DRESSER & drawer \\
\hline WAVES & FANTASY & dream & PASTE & JUICE & orange \\
\hline LOFT & HOUSE & home & THREAD & GROCERY & store \\
\hline LIME & CORE & apple & FRAME & COBWEB & spider \\
\hline BALLAD & PEDAL & bike & TUNA & FRAME & picture \\
\hline REEF & LIME & lemon & MONSOON & MITTEN & glove \\
\hline MINK & CHEF & cook & PUPPET & TURF & grass \\
\hline COLOGNE & MINK & coat & MITTEN & QUACK & duck \\
\hline BANQUET & SOCK & shoe & CRANNY & SHAMPOO & hair \\
\hline STEEPLE & KIWI & fruit & JUICE & NIECE & nephew \\
\hline TOASTER & BROOK & stream & NAVY & CRANNY & nook \\
\hline TOAD & RECORD & tape & BLEAT & TALE & story \\
\hline SENTRY & CIRCLE & square & ICING & BLEAT & sheep \\
\hline DUNE & BLOSSOM & flower & CORK & DRAM & whisky \\
\hline ACTOR & PLANET & earth & SOFA & MEAL & food \\
\hline BOUNCE & ACTOR & actress & KNIGHT & YACHT & boat \\
\hline FUNERAL & BROTHER & sister & TALE & TUNA & fish \\
\hline WICK & COLOGNE & perfume & FRECKLE & SPRAIN & ankle \\
\hline BROOK & REFLECT & mirror & STATION & GUNSHOT & wound \\
\hline DUSK & ERASER & pencil & ARTERY & THREAD & needle \\
\hline CIRCUS & SILVER & gold & SHEET & FRECKLE & face \\
\hline BUTLER & SEED & plant & BLITZ & BROTH & soup \\
\hline AIRPORT & ROMAN & empire & TWINKLE & PASTE & glue \\
\hline TALON & TIMBER & wood & CRADLE & COMB & brush \\
\hline LATHER & AIRPORT & plane & CREDIT & FATHER & mother \\
\hline SEED & BARREL & beer & FATHER & HOCKEY & stick \\
\hline WASHER & NURSE & doctor & DRESSER & STATION & train \\
\hline MARSH & BUCKLE & belt & MULE & BLITZ & war \\
\hline TORSO & CIRCUS & clown & MEAL & VINE & grape \\
\hline CASHIER & SADDLE & horse & GUNSHOT & CORK & wine \\
\hline CAPTAIN & LINK & chain & TURF & KNIGHT & armour \\
\hline DIAMOND & LATHER & soap & JIGSAW & INFANT & child \\
\hline CLAP & CIGAR & smoke & AUNT & PUPIL & student \\
\hline GIRAFFE & STEEP & hill & TENT & SOIL & dirt \\
\hline DAGGER & PLASMA & blood & SHAMPOO & PUPPET & string \\
\hline FLOOD & BREEZE & wind & NIECE & GANDER & goose \\
\hline SLEDGE & HALO & angel & SPRAIN & STORMY & weather \\
\hline HALO & HAMMER & nail & GROCERY & CRADLE & baby \\
\hline STEEP & NEST & bird & VINE & ALARM & clock \\
\hline NEST & BANNER & flag & KING & MINER & coal \\
\hline BLAZE & CASHIER & bank & STORMY & QUIVER & arrow \\
\hline CIGAR & CUTLASS & sword & QUACK & KING & queen \\
\hline BREEZE & VAGRANT & tramp & INFANT & CREDIT & card \\
\hline ERASER & MARROW & bone & SOIL & TWINKLE & star \\
\hline ALCOHOL & ESTUARY & river & PUPIL & NAVY & army \\
\hline BARREL & BUTLER & maid & GANDER & ROAR & lion \\
\hline COOKIE & SKULL & head & YACHT & FLEX & muscle \\
\hline SADDLE & BOULDER & rock & COBWEB & AUNT & uncle \\
\hline THORN & GIRAFFE & neck & TABLE & TENT & camp \\
\hline
\end{tabular}


APPENDIXA (Continued)

\begin{tabular}{|c|c|c|c|c|c|}
\hline \multicolumn{6}{|c|}{$\begin{array}{l}\text { (A2) Prime-Target Pairs for Each Nonword Target } \\
\text { (For the First } 90 \text { Items, Prime Is a Nonword; } \\
\text { for the Remaining Items, Prime Is a Word) }\end{array}$} \\
\hline Prime & Target & Prime & Target & Prime & Target \\
\hline CHOLE & flemmal & $\overline{\text { HIGTRAY }}$ & loat & SCOUT & porsen \\
\hline PONTE & falp & RABON & songar & WITNESS & linert \\
\hline BAUGER & cheg & MEASE & sultone & MORNING & lemp \\
\hline PALIVE & brank & CEARD & littase & BEACH & busp \\
\hline NINIAD & toppet & VELLOT & redont & BULL & quistor \\
\hline FERMAR & ulloy & STOAP & haroy & VICTIM & sloke \\
\hline TENK & wate & LESP & hene & BEETLE & claif \\
\hline SPALUE & motten & WOLT & kose & INJURY & calvont \\
\hline BORAM & girse & FLIPE & angone & FROST & pent \\
\hline YURD & stidach & DOSEALE & tailon & VAPOUR & malic \\
\hline SLOIGH & tunnid & MERT & bellut & RUBBER & rusket \\
\hline COBEN & swistor & TIBANNE & sarpit & PIANO & veamet \\
\hline GRINT & qualpe & SHOIF & bouser & LOAF & portnar \\
\hline REAK & poddel & STIKE & hoke & JEEP & aits \\
\hline BIQUAT & broge & TOST & buttal & GIFT & wouten \\
\hline WAMP & thembal & SNOTE & eupore & BURGLAR & mostir \\
\hline CRAT & thasdel & REAN & tharne & COTTAGE & camsor \\
\hline TRECPAR & currane & CLISH & stolip & LOCK & cremper \\
\hline REVUS & snirgle & CLORP & pulch & TRUMPET & dilter \\
\hline CHOMENT & phice & SNILTRE & daller & CASHEW & wogram \\
\hline SOANID & fepple & TAIPLE & gute & KITTEN & tennol \\
\hline HOMPLE & sogh & PONTY & cule & WARRIOR & dangion \\
\hline BRINSY & vernet & LUMN & doch & GLASS & courtle \\
\hline PANDLE & peister & TORKEL & castold & HIKER & mirt \\
\hline HELT & clurk & BIART & sute & CARAVAN & thenk \\
\hline POTIL & molt & STARM & swoid & PIGEON & luddor \\
\hline ОВОТ & gromb & HISE & suke & CRAYON & oleat \\
\hline MADDEW & ribe & QUOID & parimas & CRAB & rolth \\
\hline TAVOL & silman & CONIA & ollace & POLE & sciltop \\
\hline CIRN & oatring & DOOL & sneat & JACKAL & seln \\
\hline LAVOR & dantost & BATH & ramy & COLT & loister \\
\hline MUTAL & sordone & EPISTLE & smale & TRENCH & hestet \\
\hline POARM & deatray & WOMAN & sensip & OFFICER & cobanot \\
\hline WULST & varity & CURB & larby & SLEEVE & danter \\
\hline CORDEIN & hown & SOOT & pondal & FLASK & tartel \\
\hline VEET & clen & FLEA & passom & EMERALD & carm \\
\hline COAPS & homen & LICE & anoil & VISITOR & shoreth \\
\hline FIEM & paisun & CROSS & sorlute & KNEE & foblic \\
\hline PERIDE & wolp & SPINE & tawp & PILLOW & shealtor \\
\hline WOLCRIN & pary & TWINE & artensle & CAPE & lavet \\
\hline CEMPIST & kinnel & SUIT & casp & COFFIN & snoitre \\
\hline SLAINT & fomute & JURY & cumil & OPIUM & wrange \\
\hline SORTARY & bettun & SLAB & mord & TULIP & ampore \\
\hline PROAST & spaise & SHOVEL & pofe & DITCH & roith \\
\hline TIEL & pite & ORGAN & crund & PENGUIN & gulosy \\
\hline POISH & paltken & BALLOT & vorakle & DECK & redia \\
\hline GENK & eskygin & PELICAN & scraw & BADGE & loge \\
\hline TIRY & toin & BULB & sterp & DESERT & lacster \\
\hline MARMODE & lountry & INSECT & basty & PISTOL & sceale \\
\hline DRUST & moil & WRINKLE & fuce & COUGAR & cawbot \\
\hline CALLOGE & paip & CABBAGE & tewor & NOSE & plam \\
\hline MIPAL & bramse & GROUND & calter & KEYS & ralp \\
\hline GURNIPE & seltine & GEYSER & cuftea & VOICE & rodare \\
\hline YOLLIP & solm & ACROBAT & cobal & TROUT & togre \\
\hline SCORP & brouge & SALOON & sidge & HOSTAGE & krot \\
\hline SERPIDE & candrict & OYSTER & trealor & REFEREE & jang \\
\hline DULE & lutch & CARROT & raptole & GRAVE & belload \\
\hline SHILTOR & warkar & PRINCE & naler & PEBBLE & telt \\
\hline PILT & weng & TOPPING & datsy & DOLL & whoul \\
\hline HERNOT & triffy & PARENT & jolew & BASS & poad \\
\hline
\end{tabular}


APPENDIX B

Items Used in the Prime Detection Task: Prime-Target Pairs Where the Task Was to Classify the Prime As a Word or Nonword

(In the Experiments Reported, Only Responses

From the Last 40 Items [Four Rightmost Columns] Were Used As Data)

\begin{tabular}{|c|c|c|c|c|c|c|c|}
\hline Prime & Target & Prime & Target & Prime & Target & Prime & Target \\
\hline GENDER & female & CLOMENT & fence & COPIER & machine & ENLIT & winter \\
\hline HAZARD & danger & COTARG & clef & GLASSES & eyes & GRAFE & piece \\
\hline WEEKLY & daily & CRON & jungle & PENNY & pound & MERT & tool \\
\hline EMOTION & feeling & DAST & board & ACHIEVE & goal & FACURBY & sunday \\
\hline LAUNCH & rocket & DEBAMON & horn & GOWN & dress & EASPET & staff \\
\hline PIGMENT & skin & DOLG & white & DRAG & race & HENT & word \\
\hline SESSION & class & DONAMY & castle & MIND & brain & PHLOSE & hostess \\
\hline CANE & sugar & DORCUS & speak & SQUEAK & mouse & DATENCE & octopus \\
\hline BORDER & line & DRAUD & bandage & REPTILE & lizard & CERY & effect \\
\hline TABLET & pill & DUSS & writer & THANKS & welcome & CHIRK & sauce \\
\hline CHIEF & indian & DUTSY & maths & SOLVE & problem & NILION & shout \\
\hline KILL & murder & EBOY & package & VISION & sight & BOUSE & eight \\
\hline SHAME & guilt & ECREST & bubble & CROPS & corn & ROUP & sorrow \\
\hline COBBLER & peach & ENDES & butter & CUSTARD & pudding & SIUNT & harvest \\
\hline SALAD & lettuce & ENDLEN & rope & JUDGE & court & COSTAIN & outlet \\
\hline SUEDE & leather & ENGAL & place & NYLON & hose & SCRAUM & noise \\
\hline PYJAMAS & sleep & ENJORE & stage & DWARF & midget & SPENTER & attack \\
\hline TRAIL & path & EPON & chance & CHART & graph & SOVIN & town \\
\hline TONGUE & mouth & ERETH & blade & BARRIER & wall & IQUOD & country \\
\hline LAWSUIT & lawyer & ESTLE & school & MISTAKE & error & SAMMOR & drapes \\
\hline
\end{tabular}

(Manuscript received June 29, 2007;

revision accepted for publication August 27, 2008.) 